\title{
Vasodilator-stimulated phosphoprotein- guided Clopidogrel maintenance therapy reduces cardiovascular events in atrial fibrillation patients requiring anticoagulation therapy and scheduled for percutaneous coronary intervention: a prospective cohort study
}

Chaoyue $\mathrm{Hu}^{1 \dagger}$, Xumin Zhang ${ }^{2 \dagger}$, Yonghua Liü ${ }^{3}$, Yang Gao ${ }^{2}$, Xiaohong Zhao ${ }^{2}$, Hua Zhou², Yu Luo ${ }^{2}$, Yaling Liu ${ }^{4^{*}}$ and Xiaodong Wang ${ }^{2^{*}}$ (D)

\begin{abstract}
Background: In a previous study, we found that titrating clopidogrel maintenance doses (MDs) according to vasodilatorstimulated phosphoprotein (VASP) monitoring minimised the rate of major adverse cardiovascular and cerebral events (MACCE) after percutaneous coronary intervention (PCI) without increasing bleeding in patients with high on-treatment platelet reaction to clopidogrel. This study aimed to investigate whether VASP-guided clopidogrel MD could reduce thromboembolism and bleeding in atrial fibrillation (AF) patients requiring anticoagulation and scheduled for PCl.

Methods: AF patients scheduled for PCI were recruited between July 2014 and July 2016. These patients were allocated into VASP-guided $(n=250)$ and control $(n=253)$ groups depending on the clopidogrel MD profile. In the VASP-guided group, clopidogrel MD was titrated by the platelet reactivity index (PRI), whereas in the control group, clopidogrel MD was fixed at $75 \mathrm{mg}$ per day. The primary endpoint was MACCE and secondary endpoints were thrombolysis in myocardial infarction (TIMI) major and minor bleeding 1 year after PCl.

Results: Five hundred and three patients were included in the present study, with 1-year data available for 95.6\% patients. The average $\mathrm{CHA}_{2} \mathrm{DS}_{2}$-VASC score of the whole population was $3.7 \pm 0.7$ and the average HAS-BLED score was $3.2 \pm 0.4$. MACCE was less in the VASP-guided group than in the control group ( $2.5 \% \mathrm{vs} .5 .0 \%, P=0.02)$. The incidence of major bleeding was comparable between both groups (3.0\% vs. 2.8\%, $P=0.72)$ and minor bleeding was higher in the VASPguided group than in the control group (15.3\% vs. 9.7\%, $P=0.03)$. Kaplan-Meier analysis indicated that there was no difference in survival between both groups (log-rank test, $P=0.68$ ).
\end{abstract}

(Continued on next page)

\footnotetext{
*Correspondence: liuyaling198003@126.com; 1978wangxiaodong@163.com

${ }^{\dagger}$ Chaoyue Hu and Xumin Zhang contributed equally to this work.

${ }^{4}$ Department of Anesthesiology, Renji Hospital, Shanghai Jiaotong University

School of Medicine, 160 Pujian Road, Shanghai 200127, China

2Department of Cardiology, Shanghai East Hospital, Tongji University Schoo

of Medicine, 150 Jimo Road, Shanghai 200120, China

Full list of author information is available at the end of the article
}

(c) The Author(s). 2018 Open Access This article is distributed under the terms of the Creative Commons Attribution 4.0 International License (http://creativecommons.org/licenses/by/4.0/), which permits unrestricted use, distribution, and reproduction in any medium, provided you give appropriate credit to the original author(s) and the source, provide a link to the Creative Commons license, and indicate if changes were made. The Creative Commons Public Domain Dedication waiver (http://creativecommons.org/publicdomain/zero/1.0/) applies to the data made available in this article, unless otherwise stated. 
(Continued from previous page)

Conclusions: In AF patients requiring anticoagulation and scheduled for PCl, VASP-guided antiplatelet therapy reduced major cardiovascular and cerebral adverse events, accompanied by increased minor bleeding events.

Trial registration: The present study was retrospectively registered in the Chinese Clinical Trial Registry, A Primary Registry of the International Clinical Trial Registry Platform, World Health Organisation (Registration no: ChiCTR-IOR-17013854). The registered date was December 11, 2117.

Keywords: Atrial fibrillation, Anticoagulation, Vasodilator-stimulated phosphoprotein, Clopidogrel, Percutaneous coronary intervention

\section{Background}

Atrial fibrillation (AF) is the most common abnormal cardiac rhythm, having a high risk of thromboembolism and causing detrimental clinical outcomes. About 5 to $10 \%$ of AF patients requiring oral anticoagulation undergo coronary stent implantation [1]. This spectrum of patients requires combined therapy with oral anticoagulation, aspirin, and P2Y12 receptor blocker, which is known as triple therapy (TT). The most common combination currently consists of the vitamin $\mathrm{K}$ antagonist warfarin, and aspirin and clopidogrel.

Although TT has a potentially beneficial antithrombotic effect, prolonged TT therapy may increase bleeding risk. Current guidelines recommend the concomitant administration of TT for short consecutive periods [2]. Clopidogrel, preferred to other novel P2Y12 receptor blockers (prasugrel and ticagrelor), is the only thienopyridine recommended in guidelines. In our previous study, we found that titrating clopidogrel maintenance doses (MDs) according to vasodilator-stimulated phosphoprotein (VASP) monitoring minimised the rate of major adverse cardiovascular and cerebral events (MACCE) after percutaneous coronary intervention (PCI) without increasing bleeding in patients with high on-treatment platelet reaction (HTPR) to clopidogrel at 1-year follow-up [3].

\section{Methods}

\section{Aim}

In the present study, we aimed to clarify whether VASP-guided clopidogrel MD could decrease adverse clinical events in AF patients requiring anticoagulation and scheduled for PCI.

\section{Study design and patients}

This was a prospective cohort study that included consecutive patients with stable coronary artery disease who had AF requiring anticoagulation and were scheduled for PCI. Patients were included if they 1 ) were older than 18 years and no more than 80 years, 2) had a preexisting diagnosis of paroxysmal, persistent, or permanent AF with anticoagulation therapy warfarin, 3) had effort angina pectoris despite optimal medical therapy, and 4) had silent ischaemia on radionuclide imaging. Exclusion criteria included cardiac arrest, New York Heart Association III/IV function, platelet count $<100 \times 10^{9} / \mathrm{L}$, creatinine clearance rate $<25 \mathrm{~mL} / \mathrm{min}$.

We included patients from Shanghai East Hospital, a teaching hospital of Tongji University serving a population of approximately 5,500,000, with 12 intervention specialists and 2000 PCI procedures each year. Five hundred patients were randomly allocated to the VASP-guided and control groups. A statistician performed the allocation. Blinding was used for the participants and/or researchers. We collected data on demographic and clinical characteristics, prothrombotic risk factors, and antithrombotic therapy strategies before and after PCI. Patients' thromboembolism risk was evaluated by the $\mathrm{CHA}_{2} \mathrm{DS}_{2}$-VASc (Congestive heart failure, 1 point; Hypertension, 1 point; Age $\geq 75$ years, 2; Diabetes mellitus, 1 point; Stroke/transient ischaemic attack, 2; Vascular disease, 1 point; Age 65-74 years, 1 point; Sex category for 1) score. Bleeding risk was assessed by the HAS-BLED (Hypertension, 1; Abnormal renal and liver function, 1 point each; Stroke/ thromboembolism, 1 point; Bleeding history, 1 point; Labile INR [international normalised ratio], 1 point; Elderly [age $>65$ years], 1 point; Drug consumption and alcohol abuse, 1 point each) score. All procedures were performed according to the rules of the Ethical Committee on human clinical trials and according to the Helsinki Declaration revised in 2008. Informed written consent was obtained from all participants. The name of the registry was "Prospective randomized controlled study of anti-platelet therapy in atrial fibrillation patients undergoing percutaneous coronary intervention".

\section{Definitions}

AF was defined as paroxysmal, persistent, permanent, or unknown according to guidelines [4]. Stroke was defined as the sudden loss of neurologic function, which was classified into ischaemic or haemorrhagic and verified by brain computed tomography or magnetic resonance imaging [5]. Systemic embolism was diagnosed as acute vascular obstruction of the limbs or any organ and was verified by angiography. Acute myocardial infarction (AMI) was defined according to the universal definition of the ESC/ACCF/AHA/WHF [6]. Stent thrombosis (ST) was defined according to the Academic Research 
Consortium standard [7]. Thrombolysis in myocardial infarction (TIMI) major bleeding included intracranial or clinically significant haemorrhage with a haemoglobin decrease $>50 \mathrm{~g} / \mathrm{L}$ according to the TIMI criteria [8]. Minor bleeding was also defined according to the TIMI criteria [8].

$\mathrm{PCI}$

PCI was performed in accordance with international guidelines, using a standard technique, through the radial or femoral route [9]. A drug-eluting stent (DES) was used based on the angiography outcome. An intravenous bolus of unfractionated heparin $(100 \mathrm{IU} / \mathrm{kg})$ was administered immediately before the procedure. The administration of glycoprotein IIb/IIIa inhibitors was decided on by the attending cardiologists.

\section{Antithrombotic therapy and clopidogrel modification} Warfarin was stopped 3 days before PCI and patients were treated with low-molecular-weight heparin until $12 \mathrm{~h}$ before PCI. A combined loading dose of $300 \mathrm{mg}$ aspirin and $600 \mathrm{mg}$ clopidogrel was used before PCI. After PCI, a combined administration of $100 \mathrm{mg}$ aspirin, $75 \mathrm{mg}$ clopidogrel, and INR-monitored warfarin was continued for 3 months according to guidelines [9]. The clopidogrel MD (Plevix, $75 \mathrm{mg}$ per tablet, SANOFI, France, and clopidogrel bisulfate tablets, $25 \mathrm{mg}$ per tablet, SALUBRIS, China) fluctuated between 75 and $225 \mathrm{mg}$ for at least 1 year. All patients were treated with TT for 3 months, followed by clopidogrel plus warfarin for 9 months. VASP-adjusted clopidogrel MD commenced at the beginning of 3 months and was modified according to the VASP index in order to keep the platelet reaction index (PRI) below 50\%. VASP was monitored at 3, 6, 9, and 12 months after PCI. The stepwise increase of clopidogrel dosage was adopted. After the first PRI monitoring, $100 \mathrm{mg}$ clopidogrel was administered if PRI $>50 \%$. The second PRI monitoring was undertaken 6 months after PCI, and $125 \mathrm{mg}$ clopidogrel was administered if PRI was still $>50 \%$. Subsequent additional doses were similar to the previous doses. Another $25 \mathrm{mg}$ clopidogrel was given if PRI $>50 \%$ after every 3 months. The maximum clopidogrel MD at the end of 1 year was $175 \mathrm{mg}$. If PRI $<25 \%$, clopidogrel MD was decreased to $75 \mathrm{mg}$. If PRI $>25 \%$ and was $<50 \%$, the dose was not changed and the determined dose was maintained.

\section{Blood samples}

Three months after PCI, blood samples were drawn from the antecubital vein once every 3 months. The initial blood was removed to avoid platelet activation induced by the puncture action. Blood was transferred into a tube with $3.8 \%$ trisodium citrate. The tube was gently inverted up and down 3 to 5 times and was immediately sent to the monitoring laboratory.

\section{VASP phosphorylation test}

The VASP phosphorylation test was performed more than $1 \mathrm{~h}$ after blood collection by an experienced technician using Platelet VASP kits (Becton Dickinson, USA) according to the instruction manual [10]. Briefly, blood samples were mixed in vitro with adenosine diphosphate (ADP) and/or prostaglandin E1 (PGE1). Each blood sample was incubated with a 16C2FITC antibody, followed by a goat anti-mouse fluorescence staining in isothiocyanate polyclonal reagent. Flow cytometric monitoring was conducted with a Coulter EPICS XL cytometer (CA, U.S.A). The platelet group was identified on its side scatter and forward distributions. Every 3000 platelet events were gated and analysed for mean fluorescence intensity (MFI) using flow cytometry. The MFI corresponding to each experimental situation (ADP and ADP + PGE1) was determined to calculate a ratio directly related to the VASP phosphorylation value. The ratio, $\left[\left(\mathrm{MFI}_{\mathrm{PGE1}}-\mathrm{M}-\right.\right.$ $\left.\left.\mathrm{FI}_{\mathrm{ADP}+\mathrm{PGE}}\right) / \mathrm{MFI}_{\mathrm{PGE1}}\right] \times 100 \%$, which indicates a percentage of platelet reactivity, is expressed as a PRI corresponding to a ratio of activated platelets versus resting platelets.

\section{INR monitoring}

For all patients who received warfarin, the predicted INR was set between 2.0 and 2.5 according to guidelines [2]. INR was regularly monitored after discharge. In the beginning, INR evaluations were performed every week after discharge. If the INR achieved the target range after monitoring three consecutive times, the measurement was then taken monthly.

\section{Clinical endpoint}

For the clinical follow-up, the primary endpoint was designated as the occurrence of MACCE, involving cardiovascular death, myocardial infarction (MI), target vessel revascularisation (TVR), ST, systemic embolism, and stroke. Secondary endpoints were defined as TIMI major and minor bleeding.

\section{Follow-up}

The clinical follow-up involved a clinic visit or telephone interview at 3, 6, 9, and 12 months after PCI. If a dose adjustment was made at 9 months, the patients were followed up for another 1 year from then on. The MD modification was as before. All patients with symptoms during the visit and interview were evaluated by at least two cardiologists. Death or MI events were recorded by hospital admission staff or community service. 


\section{Statistics}

Continuous variables are described as mean \pm SD and categorical variables as numbers and percentages. Differences between treatment groups were tested with one-way or two-way repeated-measures ANOVA, followed by Bonferroni correction for intergroup comparisons. Comparison between categorical variables was performed with the Chi-square test or Fisher exact test if frequencies were no more than 5. Event-free survival rates in different groups were calculated by Kaplan-Meier survival analysis and compared by the log-rank test. A two-sided $P$-value of $<0.05$ was considered statistically significant. Data statistics were performed using Prism 5.0 (GraphPad Software, CA, USA).

\section{Results}

We prospectively recruited 503 patients with AF requiring anticoagulation and who underwent PCI between July 2014 and July 2017; 481 patients (VASP-guided, $n=241$; control, $n=240$ ) completed the 1-year follow-up (Fig. 1). In the VASP-guided and control groups, 89.7 and $89.9 \%$ of patients, respectively, had paroxysmal or persistent/permanent AF. The clinical and procedural characteristics and other medical histories were comparable between both groups. In the VASP-guided and control groups, the $\mathrm{CHA}_{2} \mathrm{DS}_{2}$-VASc score was $3.7 \pm 0.6$ and $3.8 \pm 0.9$, respectively, whereas, the HAS-BLED score was $3.1 \pm 0.4$ and 3.3 \pm 0.5 , respectively, indicating high thrombotic and bleeding risk profiles in both groups. The average INR on the day of the procedure was $1.2 \pm 0.6$ and $1.3 \pm 0.7$, respectively, indicating unsatisfactory warfarin therapy in both groups (Table 1).

\section{Antithrombotic mediation after discharge}

For patients prescribed antithrombotic therapy after discharge, there was high compliance in both groups. The median duration of TT and clopidogrel plus warfarin was 3.2 and 9.5 months, respectively. There was no difference in duration between $\mathrm{CHA}_{2} \mathrm{DS}_{2}$-VASc 1 or $\geq 2$ and HASBLED $\leq 2$ or $\geq 3$ (Table 2).

\section{PRI}

We analysed PRI at a mean time of 3, 6, 9, and 12 months after the PCI procedure. The baseline PRI showed no significant difference between both groups $(73.5 \pm 12.7 \%$ [VASP] vs $68.4 \pm 17.2 \%$ [control], $P=0.4$ ). PRI in the VASP-guided group decreased significantly $(73.5 \pm 12.7 \%$, $32.3 \pm 4.9 \%, 35.5 \pm 6.7 \%$, and $29.8 \pm 7.3 \%$ at $3,6,9$, and 12 months after randomisation, respectively; $P=0.001$ ); PRI in the control group also decreased, but not significantly $(68.4 \pm 17.2 \%, 48.5 \pm 13.2 \%, 51.6 \pm 19.8 \%$, and 65.3 $\pm 17.2 \%$, respectively; $P>0.5$ ). Compared to the control group, PRI in the VASP-guided group was significantly lower $(P=0.04,0.03$, and $<0.001$ at 6,9 , and 12 months after randomisation, respectively) (Table 3 ).

\section{Clopidogrel dose modification}

Clopidogrel MD in the VASP-guided group was modified according to PRI. The number of patients that required clopidogrel MD individualisation was 162 (67.3\%), 181 (75.4\%), 197 (81.9\%), and 208 (86.3\%) at 3, 6, 9, and 12 months, respectively (Fig. 2). Regarding MD according to PRI at 3, 6, 9, and 12 months, 132 (81.5\%), $100(55.2 \%), 70$ (35.5\%), and $40(19.4 \%)$ patients, respectively, had increased MD, 22 (13.6\%), 41 (22.6\%), 93 $(47.2 \%)$, and $130(63.1 \%)$ patients, respectively, had unchanged MD, while 8 (4.9\%), 40 (22.1\%), 34 (17.3\%), and $36(17.5 \%)$ patients, respectively had decreased MD (Fig. 3). At the study's completion, 33 of 241 (13.7\%) patients in the VASP-guided group still had HTPR $>50 \%$ (data not shown).

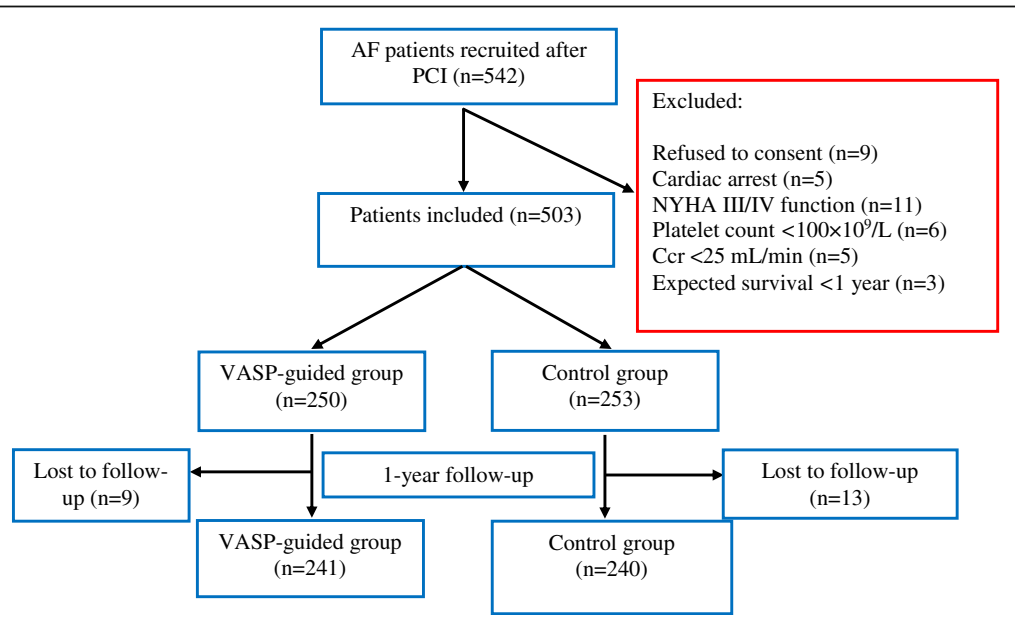

Fig. 1 Study flowchart and follow-up. AF: atrial fibrillation; CCr: creatinine clearance rate; NYHA: New York Heart Association; PCl: percutaneous coronary intervention; VASP: vasodilator-stimulated phosphoprotein 
Table 1 Clinical, medical, and procedural characteristics

\begin{tabular}{|c|c|c|c|}
\hline Characteristics & VASP-guided group & Control group & $P$-value \\
\hline & $(n=241)$ & $(n=240)$ & \\
\hline Age (y) & $64.4 \pm 3.2$ & $62.8 \pm 4.3$ & 0.58 \\
\hline Age $\geq 75$ years & $61(25.3)$ & $64(26.7)$ & 0.72 \\
\hline Men & 128(53.4) & $122(50.8)$ & 0.62 \\
\hline BMI $\left(\mathrm{kg} / \mathrm{m}^{2}\right)$ & $26.7 \pm 4.2$ & $25.3 \pm 2.1$ & 0.88 \\
\hline Current Smoker & $87(36.2)$ & $96(40.1)$ & 0.55 \\
\hline \multicolumn{4}{|l|}{ AF category } \\
\hline Paroxysmal & $92(38.4)$ & $96(40.2)$ & 0.7 \\
\hline Persistent/permanent & 123(51.3) & 119(49.7) & 0.84 \\
\hline Unknown & 26(10.3) & $25(10.1)$ & 0.98 \\
\hline \multicolumn{4}{|l|}{ Medical history } \\
\hline Diabetes & $68(28.4)$ & 75(31.3) & 0.43 \\
\hline Hypertension & $141(58.8)$ & $144(60.3)$ & 0.57 \\
\hline Previous heart failure & $41(17.1)$ & $52(21.9)$ & 0.19 \\
\hline Previous stroke or & $25(10.3)$ & 28(11.6) & 0.65 \\
\hline \multicolumn{4}{|l|}{ thromboembolism } \\
\hline Previous bleeding & $16(6.7)$ & $13(5.5)$ & 0.53 \\
\hline CHA2DS2 -VASC Score & $3.7 \pm 0.6$ & $3.8 \pm 0.9$ & 0.87 \\
\hline CHA2DS2 -VASc Score $\geq 2$ & 174(72.4) & $168(70.3)$ & 0.35 \\
\hline HAS-BLED Score & $3.1 \pm 0.4$ & $3.3 \pm 0.5$ & 0.76 \\
\hline HAS-BLED Score $\geq 3$ & $61(25.3)$ & $59(24.8)$ & 0.64 \\
\hline LVEF & $52.3 \pm 4.4$ & $51.0 \pm 3.9$ & 0.59 \\
\hline \multicolumn{4}{|l|}{ Treatment on admission } \\
\hline Previous aspirin & $31(12.8)$ & $33(14.0)$ & 0.21 \\
\hline Previous clopidogrel & $13(5.4)$ & $14(7.3)$ & 0.48 \\
\hline Previous oral anticoagulation & $131(54.3)$ & 119(49.7) & 0.65 \\
\hline \multicolumn{4}{|c|}{ Indication for the catheterisation procedure } \\
\hline Stable angina & 188(78.5) & 168(70.2) & 0.74 \\
\hline Silent myocardial ischaemia & $52(21.5)$ & $71(29.8)$ & 0.17 \\
\hline Platelet (×109/L) & $202 \pm 23$ & $183 \pm 17$ & 0.28 \\
\hline $\mathrm{Cr}(\mu \mathrm{mmol} / \mathrm{L})$ & 98.3 & 89.4 & 0.13 \\
\hline Mean INR on day of procedure & $1.2 \pm 0.6$ & $1.3 \pm 0.7$ & 0.72 \\
\hline \multicolumn{4}{|l|}{ Pharmacotherapy } \\
\hline RAS inhibitors & 212(88.2) & $200(83.5)$ & 0.61 \\
\hline Statins & 237(98.3) & 237(98.7) & 0.98 \\
\hline$\beta$-Blockers & 123(51.4) & 132(55.3) & 0.76 \\
\hline Digoxin & $32(13.4)$ & $41(17.2)$ & 0.25 \\
\hline Amiodarone & $62(25.9)$ & $46(19.4)$ & 0.09 \\
\hline \multicolumn{4}{|l|}{ Procedural characteristics } \\
\hline No. of lesions treated per patient & 1.4 & 1.5 & 0.88 \\
\hline No. of stents per patient & 1.3 & 1.2 & 0.64 \\
\hline Patients receiving DES & $241(100)$ & $240(100)$ & 1 \\
\hline GP ॥b/llla inhibitors & $61(25.4)$ & $67(28.1)$ & 0.38 \\
\hline
\end{tabular}

Values are presented as mean \pm SD or $\mathrm{n}(\%)$

$A F$ atrial fibrillation, $B M I$ body mass index, Cr creatinine, GP glycoprotein, INR international normalised ratio, LVEF left ventricular ejection fraction, $R A S$ renin-angiotensin system 
Table 2 Antithrombotic drug regimen at discharge

\begin{tabular}{|c|c|c|c|c|c|}
\hline \multirow[t]{2}{*}{ Medication } & \multicolumn{5}{|c|}{ Median duration (months) } \\
\hline & $\mathrm{CHA}_{2} \mathrm{DS}_{2}-\mathrm{VASC}=1$ & $\mathrm{CHA}_{2} \mathrm{DS}_{2}-\mathrm{VASC} \geq 2$ & HASBLED $\leq 2$ & HASBLED $\geq 3$ & $P$-value \\
\hline Aspirin & $2.3 \pm 0.7$ & $3.2 \pm 1.1$ & $3.8 \pm 0.9$ & $3.3 \pm 0.9$ & $>0.05$ \\
\hline Clopidogrel & $11.2 \pm 2.8$ & $12.9 \pm 1.4$ & $12.6 \pm 2.5$ & $10.3 \pm 1.6$ & $>0.05$ \\
\hline Warfarin & $10.5 \pm 2.8$ & $12.4 \pm 1.3$ & $11.8 \pm 2.1$ & $10.8 \pm 2.7$ & $>0.05$ \\
\hline
\end{tabular}

\section{INR monitoring}

During the 1-year follow-up, INR was measured at least every month. The representative value at 1, 3, 6, 9 and 12 months are listed in Table 4. INR increased at 12 months compared to baseline only in patients with $\mathrm{CHA}_{2} \mathrm{DS}_{2}$-VASc score $\geq 2$ (from $1.9 \pm 0.3$ to $2.5 \pm 0.8$, $P<0.05)$.

\section{Clinical outcomes during follow-up}

Complete follow-up (median 365 days; range 300 to 395 days) was recorded in $95.6 \%$ of the whole cohort. The clinical events recorded in the two groups are shown in Table 5. The incidences of TVR and all MACCE were higher in the control group than in the VASP-guided group, whereas the occurrence of cardiovascular death, MI, ST, systemic embolism, and stroke was not significantly different between both groups. Regarding the secondary endpoints, major bleeding incidence was comparable between both groups, whereas the rate of minor bleeding was significantly higher in the VASP-guided group ( $15.3 \%$ vs $9.7 \%, P=0.032$ ). Kaplan-Meier survival analysis demonstrated that there was no statistical difference between the VASP-guided and control groups during the 1-year follow-up (log-rank test $P=0.68$ ) (Fig. 4).

\section{Discussion}

To our knowledge, this is the first prospective study to show that individualised clopidogrel MD according to platelet function reduced the incidence of MACCE in AF patients requiring anticoagulation and scheduled for PCI. However, an increase in minor bleeding was noted. The study shows that our patients had a high risk of stroke and bleeding. Our clinical data demonstrate the protective effect of individualised clopidogrel MD in patients with AF undergoing PCI by decreasing the incidence of adverse clinical events, without increasing major bleeding.

Owing to lack of well-founded evidence to date, there has been no consensus on the optimal therapy regarding the antithrombotic strategy for AF patients requiring chronic anticoagulation and coronary stent implantation. Most previous studies evaluating TT have either been small-scale retrospective or case-control clinical trials focusing on bleeding risk. Thus, there is a lack of evidence to support optimal medical therapy regarding the cardiovascular efficacy of different antithrombotic regimens. In the largest observational study of AF patients with stable coronary artery disease in Denmark, the addition of antiplatelet therapy (either aspirin or clopidogrel) to vitamin $\mathrm{K}$ antagonist therapy decreased recurrent cardiovascular events or thromboembolism but increased bleeding significantly [11]. In that study and in the present study, the high $\mathrm{CHA}_{2} \mathrm{DS}_{2}$-VASc score indicated a high thrombotic risk in both cohorts. The greater number of bleeding events in the previous study might be attributed to racial differences or the fixed TT strategy.

In the Karjalainen et al. [12] case-control study, warfarin plus aspirin failed to prevent more cardiovascular events. However, this combination increased the risk for stent thrombosis. In the study by Ruiz-Nodar et al. [13] regarding combined therapy with coumarins, aspirin, and clopidogrel, the incidence of adverse events in TT was low, with no increase in minor and major bleeding compared to dual antiplatelet therapy (DAPT). The prospective multicentre registry study, STENTICO, demonstrated an increase in severe and moderate GUSTO bleeding in TT compared to DAPT [14]. In addition, the AVIATOR Registry study [15], involving patients that received TT or DAPT, showed similar MACE rates, with a higher BARC $\geq 2$ bleeding when discharged. In a prospective multicentre

Table 3 Platelet Reactivity Index (PRI) in the two groups during the 1-year study

\begin{tabular}{|c|c|c|c|c|c|}
\hline & PRI (mean \pm & & & & \\
\hline & 3 months & 6 months & 9 months & 12 months & $P$-value* \\
\hline & after randor & & & & \\
\hline Control group & $68.4 \pm 17.2$ & $48.5 \pm 13.2$ & $51.6 \pm 19.8$ & $65.3 \pm 17.2$ & $>0.05$ \\
\hline VASP-guided group & $73.5 \pm 12.7$ & $32.3 \pm 4.9$ & $35.5 \pm 6.7$ & $29.8 \pm 7.3$ & 0.001 \\
\hline$P$-value\# & 0.4 & 0.04 & $<0.001$ & 0.03 & $<0.001$ \\
\hline
\end{tabular}

VASP vasodilator-stimulated phosphoprotein

*comparison between $3,6,9$, and 12 months

"comparison between the control group and VASP-guided group 


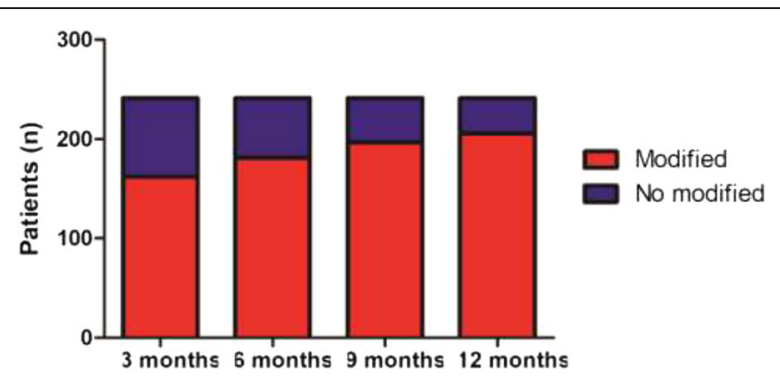

Fig. 2 Patient distribution according to the modified or unmodified clopidogrel maintenance dose in the VASP-guided group. VASP: vasodilator-stimulated phosphoprotein

study [16], TT was compared to DAPT in patients with AF undergoing PCI. The results showed that patients with a low $\mathrm{CHA}_{2} \mathrm{DS}_{2}$-VASc score had a high risk of bleeding without any benefit in reducing thromboembolic events. It also demonstrated that TT decreased the thromboembolism rate at the expense of an increase in major bleeding in patients with high $\mathrm{CHA}_{2} \mathrm{DS}_{2}$-VASc scores. These studies show the variability of antithrombotic agents in this kind of patients. There is no one-size-fits-all strategy for balancing thrombotic and bleeding risk.

In the present study, TT was used for an average of 3 months in all patients, which might be one reason major bleeding risk did not increase during the 1-year follow-up. Recently, the ISAR-TRIPLE trial [17] evaluated the effect of clopidogrel in addition to concomitant aspirin and warfarin following DES implantation. The study showed no significant difference in MACCE between 6 months and 6 weeks of TT. Furthermore, a longer duration of TT did not increase the bleeding risk in this study. This added evidence supports limiting the duration of DAPT and individualising therapy based on the patient's risk profile. In a recent study [18], 568 patients receiving TT were prospectively investigated according to a 1-month or $>1$-month regimen. The endpoints of primary safety and secondary bleeding were not significantly different between both groups. The study suggested that 30 -day TT had similar clinical outcomes compared to longer TT durations. Because of the involvement of high-thrombotic-risk patients in the present study and guideline recommendations [2], we administered TT for 3 months.

Few trials have focused on antithrombotic therapy in Asian patients, particularly Chinese patients, who have undergone $\mathrm{PCI}$ and require oral anticoagulation. A prospective study involving 142 Chinese patients discharged with TT demonstrated a notable decrease in stroke and MACCE and its major bleeding risk might have fallen within acceptable ranges if the INR was strictly monitored [19]. In that study, the overall major adverse events in the TT group was $8.8 \%$, and major and minor bleeding were 2.9 and $8.8 \%$, respectively. In our present study, the major adverse events were $2.5 \%$ in the VASP-guided group and $5.0 \%$ in the control group, and major and minor bleeding were 2.8 to $3 \%$ and 9.7 to $15.3 \%$, respectively. The difference between our study and theirs might be explained by the thrombotic risk of patients; the present study had a high-thrombotic-risk cohort $\left(\mathrm{CHA}_{2} \mathrm{DS}_{2}\right.$-VAScScore $\left.\geq 2,71.5 \%\right)$. Another study with a small cohort of 37 patients requiring TT was conducted in South Korea [20]. The authors concluded that warfarin therapy reduced major adverse events without increasing bleeding risk. In that study, the percentage of $\mathrm{CHADS}_{2}$ score $\geq 2$ was $56.8 \%$, whereas, all major adverse events and any bleeding were 0.97 and $1.94 \%$, respectively. These differences may be attributed to the nationality and sample size, although this study was conducted in Asia.

Inter-individual variability of clopidogrel has been frequently reported and has been regarded as "clopidogrel resistance" and HTPR [21]. Hyporesponse to clopidogrel with a high risk of coronary ischaemia and hyper response to clopidogrel with a high risk of bleeding results in an increase in cardiovascular events. Clinical factors including diabetes, poor absorption, and drug-drug interactions may be one aspect of HTPR [21]. Genetic factors are another aspect to consider. The polymorphism of dominant genes such as CYP2C19, $A B C B 1, P 2 Y 12$, and $T 2238 C$ result in

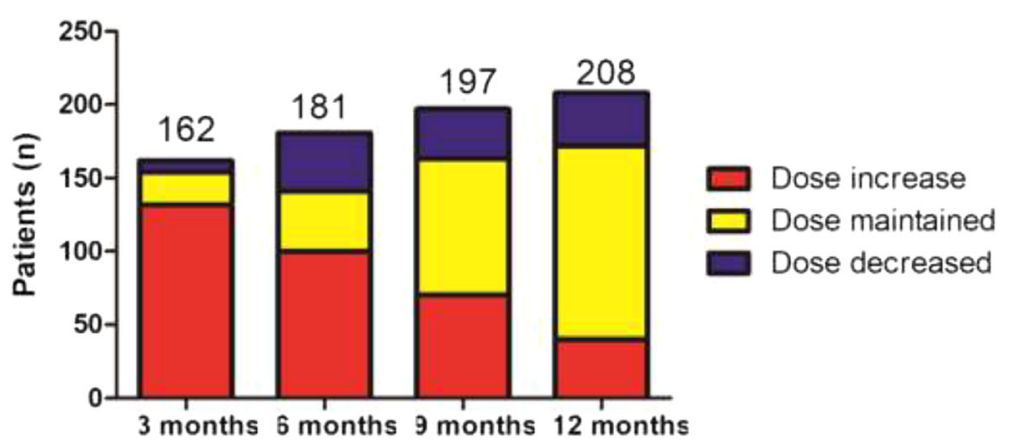

Fig. 3 Patient distribution according to the clopidogrel maintenance dose modification profile in the VASP-guided group. VASP: vasodilator-stimulated phosphoprotein 
Table 4 INR monitoring during the 1-year follow-up

\begin{tabular}{lllllll}
\hline Categories & $1 \mathrm{mo}$ & $3 \mathrm{mo}$ & $6 \mathrm{mo}$ & $9 \mathrm{mo}$ & $12 \mathrm{mo}$ & $P$-value \\
\hline VASP-guided group & $1.8 \pm 0.3$ & $2.1 \pm 0.5$ & $1.9 \pm 0.7$ & $2.0 \pm 0.2$ & $2.2 \pm 0.4$ & 0.33 \\
Control group & $1.7 \pm 0.9$ & $2.0 \pm 0.3$ & $2.1 \pm 0.5$ & $1.9 \pm 0.6$ & $2.1 \pm 0.2$ & 0.48 \\
CHA2DS2-VASc Score $=1$ & $2.0 \pm 0.2$ & $1.7 \pm 0.4$ & $2.2 \pm 0.9$ & $2.0 \pm 0.8$ & $2.1 \pm 0.7$ & 0.56 \\
CHA2DS2-VASc Score $\geq 2$ & $1.9 \pm 0.3$ & $1.6 \pm 0.6$ & $2.3 \pm 0.5$ & $2.6 \pm 0.9$ & $2.5 \pm 0.8$ & $<0.05$ \\
HAS-BLED Score $<2$ & $1.6 \pm 0.5$ & $1.8 \pm 0.4$ & $2.0 \pm 0.6$ & $2.1 \pm 0.4$ & $2.2 \pm 0.7$ & 0.14 \\
HAS-BLED Score $\geq 3$ & $1.7 \pm 0.2$ & $1.9 \pm 0.5$ & $2.1 \pm 0.6$ & $2.2 \pm 0.4$ & $2.1 \pm 0.8$ & 0.35 \\
\hline
\end{tabular}

P-value: 1 month vs. 12 months

HTPR, especially in Chinese patients [22-26]. Furthermore, the gene-based individualised clopidogrel strategy demonstrated no benefit from GRAVITAS [27], ARCTIC [28], Trigger-PCI [29], and ANTARCTIC [30].

In all patients in the present study, during the 1-year follow-up, INR was rigorously monitored and was within the therapeutic range. Our results from the present study demonstrate that the TT-induced bleeding risk will fall within acceptable ranges if INR is rigorously monitored. Likewise, the ACTIVE-W trial recorded a significant benefit from anticoagulation combined with DAPT in AF patients. The ACTIVE-W study also demonstrated that patients benefitted from anticoagulation therapy, with INR values within the therapeutic range [31].

Another problem is the use of the drug-eluting stent (DES) for AF patients, which is the predominant implantation scaffold for coronary intervention. DES use is also inevitably associated with delayed neointimal recovery and an increased risk of late ST, resulting in prolonged DAPT for up to 1 year. However, in patients requiring oral anticoagulation, prolonged DAPT may increase major bleeding risk [14]. Therefore, the use of bare metal stents (BMS) was suggested by some studies for such patients $[32,33]$ and DES should be implanted only in situations such as long lesions, small vessels, and

Table 5 Outcomes during the follow-up

\begin{tabular}{|c|c|c|c|}
\hline Outcomes & $\begin{array}{l}\text { VASP-guided group } \\
n=241\end{array}$ & $\begin{array}{l}\text { Control group } \\
n=240\end{array}$ & $P$-value \\
\hline Cardiovascular death & $1(0.4)$ & $2(0.8)$ & 0.34 \\
\hline Ml & $1(0.4)$ & $2(0.8)$ & 0.34 \\
\hline TVR & $1(0.4)$ & $3(1.3)$ & 0.03 \\
\hline Stent thrombosis & $1(0.4)$ & $1(0.4)$ & 0.21 \\
\hline Systemic embolism & $1(0.4)$ & $2(0.8)$ & 0.34 \\
\hline Stroke & $1(0.4)$ & $2(0.8)$ & 0.34 \\
\hline All MACCE & $6(2.5)$ & $12(5.0)$ & 0.02 \\
\hline TIMI major bleeding & $7(3.0)$ & $6(2.8)$ & 0.72 \\
\hline TIMI minor bleeding & $37(15.3)$ & $23(9.7)$ & 0.03 \\
\hline
\end{tabular}

Values are presented as $\mathrm{n}(\%)$

MACCE major adverse cardiovascular and cerebral event, $M I$ myocardial infarction, TIMI thrombolysis in myocardial infarction, TVR target vessel revascularisation diabetes, in which the significant advantages of DES outweigh the disadvantages of BMS [34]. In our study, the scaffold used was exclusively DES. Individualised clopidogrel MD and close INR monitoring might overcome the disadvantages of DES in long-term antithrombotic therapy.

In the SPORTIF trial [35], the addition of aspirin to oral anticoagulants (INR 2.0-3.0) increased major bleeding risk without decreasing thromboembolism or AMI in AF patients. In addition, results from the WOEST trial [36] showed a significant increase in death and MI events in those who received vitamin $K$ antagonist plus DAPT than in those treated with vitamin $\mathrm{K}$ antagonist plus clopidogrel. These results demonstrate that in patients whose bleeding risk surpasses stroke risk, combined warfarin and clopidogrel would be a reasonable treatment choice. In the present study, the average HAS-BLED score was 3.1, which indicated a relatively high-bleeding cohort. Consequently, we chose the close monitoring of warfarin and modified clopidogrel plus fixed aspirin for 3 months. The strategy was also in accordance with the consensus of antithrombotic therapy in AF patients with a combination of ACS and/or undergoing PCI [2].

The interaction of warfarin and clopidogrel was investigated in the Sibbing et al. study [37], in which they reported that both clopidogrel and phenprocoumon were metabolised synchronously through the hepatic cytochrome P450 system and there was an intra-drug interaction at this level. The result demonstrated that

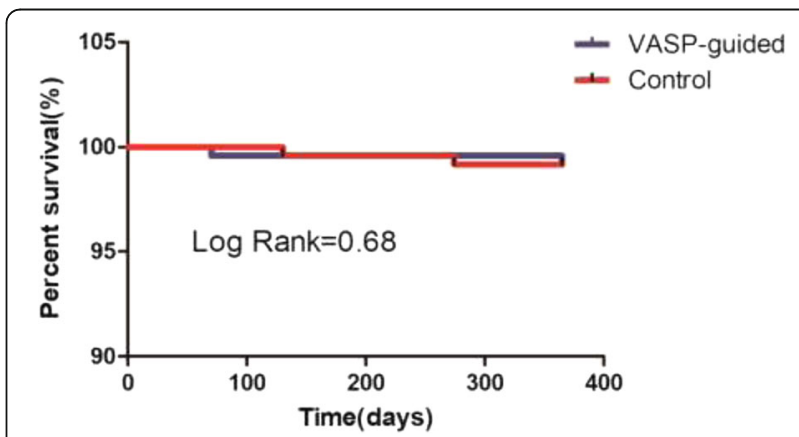

Fig. 4 Kaplan-Meier curves of survival during the 1-year follow-up. VASP: vasodilator-stimulated phosphoprotein 
phenprocoumon notably attenuated the antiplatelet effect of clopidogrel. If this is true, the VASP-guided clopidogrel therapy compensated for the attenuation of warfarin on antiplatelet effects in the current study.

To date, only two studies have investigated the effect of prasugrel on TT strategy. In the Sarafoff et al. study [38], aspirin, prasugrel, and vitamin $\mathrm{K}$ antagonist were prescribed for 6 months. Compared to clopidogrel, prasugrel increased the bleeding risk in patients requiring TT. In the TRANSLATE-ACS study [39] of AMI patients treated with PCI, clopidogrel or prasugrel was administered in addition to aspirin and anticoagulant. The study concluded that among patients with TT, prasugrel administration was associated with a higher bleeding risk. Thus, prasugrel was not recommended in the consensus document.

Because of the high bleeding risk, a new oral anticoagulant therapy was evaluated. The RE-DUAL PCI study [40] compared TT with warfarin plus a P2Y12 antagonist (clopidogrel or ticagrelor) and aspirin (TT group) to dual therapy with dabigatran plus a P2Y12 antagonist (clopidogrel or ticagrelor) and no aspirin. The results demonstrated that among AF patients undergoing $\mathrm{PCI}$, the bleeding risk was lower in patients who received the latter combination than in patients who received the former. Dual therapy was non-inferior to TT with respect to the risk of thromboembolism. In the PIONEER AF-PCI study [41], the combination of either low-dose rivaroxaban plus a P2Y12 antagonist or very-low-dose rivaroxaban plus DAPT significantly decreased the bleeding risk compared to standard therapy with a vitamin $K$ antagonist plus DAPT for 1,6 , or 12 months. These two studies met the objective of decreasing bleeding risk; however, they exhibited no significant difference regarding thrombotic events. In addition, neither dabigatran nor rivaroxaban is used regularly in the real world, especially in China.

\section{Limitations}

There are some limitations to the present study. First, the study was conducted in the Chinese population, which demonstrates more "clopidogrel resistance" than the European and North American populations, so the conclusion should be cautiously extended to others. Second, the sample of patients recruited in the present study was relatively small. Third, the present study did not evaluate the effects of the new antiplatelet ticagrelor or new anticoagulants such as dabigatran or rivaroxaban. In the future, we will focus on the antithrombotic effect of these antagonists.

\section{Conclusion}

The present study verified that a modified clopidogrel maintenance strategy combined with aspirin and warfarin therapy decreased adverse cardiovascular events at the cost of increasing minor bleeding.

\begin{abstract}
Abbreviations
ADP: adenosine diphosphate; AF: atrial fibrillation; AMl: Acute myocardial infarction; DAPT: dual antiplatelet therapy; DES: drug-eluting stent; HTPR: high ontreatment platelet reaction; INR: international normalised ratio; MACCE: major adverse cardiovascular and cerebral events; MD: maintenance dose; MFI: mean fluorescence intensity; PCl: percutaneous coronary intervention;

PGE1: prostaglandin E1; PRI: platelet reactivity index; ST: stent thrombosis;

TIMI: thrombolysis in myocardial infarction; TT: triple therapy; TVR: target vessel revascularisation; VASP: vasodilator-stimulated phosphoprotein
\end{abstract}

\section{Funding}

The present study was supported by the Science and Technology Commission of Shanghai Municipality (No. 17411968500) and the Key Disciplines Group Construction Project of Pudong Health Bureau of Shanghai (Grant No. PWZxq2017-05). The former helped fund the design of the study, collection, analysis, and interpretation of data. The latter helped fund the writing the manuscript.

\section{Availability of data and materials}

The datasets used during the current study are available from the corresponding author on reasonable request.

\section{Authors' contributions}

$\mathrm{CH}$ collected all patients clinical and laboratory data, involving platelet activity index and anticoagulation function monitoring data and made major statistical analysis. XZ finished the follow-up during one-year follow-up and analyzed the relationship between triple/dual therapy and the clinical outcome. YG performed platelet activity examination in control group during one-year follow-up. XZ finished platelet activity examination in the VASPguided group. YL1 performed coagulation examination in control group patients. $\mathrm{HZ}$ and $\mathrm{YL} 2$ performed the coagulation examination for every patient in the VASP-guided group. YL3 wrote the primary draft of this manuscript. XW put forward the conception of the study, conducted the proposal and revised the manuscript. All authors read and approved the final manuscript.

\section{Ethics approval and consent to participate}

All procedures were performed in accordance with rules of the Ethical Committee of Shanghai East Hospital, Tongji University on human clinical trials and in accordance with the Helsinki Declaration revised in 2008. This study was approved by the Medical Ethics Committee of Shanghai East Hospital, Tongji University School of Medicine. Informed written consent was obtained from all participants.

\section{Competing interests}

The authors declare that they have no competing interests.

\section{Publisher's Note}

Springer Nature remains neutral with regard to jurisdictional claims in published maps and institutional affiliations.

\section{Author details}

${ }^{1}$ Key Laboratory of Arrhythmias of the Ministry of Education of China, Tongji University School of Medicine, Shanghai 200092, China. 'Department of Cardiology, Shanghai East Hospital, Tongji University School of Medicine, 150 Jimo Road, Shanghai 200120, China. ${ }^{3}$ Cardiovascular Medicine of Baoshan People's Hospital of Yunnan Province, Baoshan 678000, China. ${ }^{4}$ Department of Anesthesiology, Renji Hospital, Shanghai Jiaotong University School of Medicine, 160 Pujian Road, Shanghai 200127, China.

Received: 12 March 2018 Accepted: 31 May 2018

Published online: 18 June 2018

\section{References}

1. Schömig A, Sarafoff N, Seyfarth M. Triple antithrombotic management after stent implantation: when and how? Heart. 2009;95:1280-5.

2. Lip GY, Windecker S, Huber K, Kirchhof P, Marin F, Ten Berg JM, et al. Management of antithrombotic therapy in atrial fibrillation patients presenting with acute coronary syndrome and/or undergoing percutaneous coronary or valve interventions: a joint consensus document of the European Society of Cardiology Working Group on Thrombosis, European Heart Rhythm Association (EHRA), European Association of Percutaneous 
Cardiovascular Interventions (EAPCI) and European Association of Acute Cardiac Care (ACCA) endorsed by the Heart Rhythm Society (HRS) and AsiaPacific Heart Rhythm Society (APHRS). Eur Heart J. 2014;35:3155-79.

3. Wang XD, Zhang DF, Zhuang SW, Lai Y. Modifying clopidogrel maintenance doses according to vasodilator-stimulated phosphoprotein phosphorylation index improves clinical outcome in patients with clopidogrel resistance. Clin Cardiol. 2011;34:332-8.

4. Kirchhof P, Benussi S, Kotecha D, Ahlsson A, Atar D, Casadei B, et al. 2016 ESC guidelines for the management of atrial fibrillation developed in collaboration with EACTS. Eur Heart J. 2016:37:2893-962.

5. Whiteley WN, Slot KB, Fernandes P, Sandercock P, Wardlaw J. Risk factors for intracranial hemorrhage in acute ischemic stroke patients treated with recombinant tissue plasminogen activator: a systematic review and metaanalysis of 55 studies. Stroke. 2012;43:2904-9.

6. Thygesen K, Alpert JS, Jaffe AS, Simoons ML, Chaitman BR, White HD. Third universal definition of myocardial infarction. Circulation. 2012;126:2020-35.

7. Cutlip DE, Windecker S, Mehran R, Boam A, Cohen DJ, van Es GA. Academic Research Consortium. Clinical end points in coronary stent trials: a case for standardized definitions. Circulation. 2007;115:2344-51.

8. Rao AK, Pratt C, Berke A, Jaffe A, Ockene I, Schreiber TL. Thrombolysis in myocardial infarction (TIMI) trial—phase l: hemorrhagic manifestations and changes in plasma fibrinogen and the fibrinolytic system in patients treated with recombinant tissue plasminogen activator and streptokinase. J Am Coll Cardiol. 1988;11:1-11.

9. Windecker S, Kolh P, Alfonso F, Collet JP, Cremer J, Falk V, et al. 2014 ESC/ EACTS guidelines on myocardial revascularization: the task force on myocardial revascularization of the European Society of Cardiology (ESC) and the European Association for Cardio-Thoracic Surgery (EACTS) developed with the special contribution of the European Association of Percutaneous Cardiovascular Interventions (EAPCI). Eur Heart J. 2014;35:2541-619.

10. Bonello L, Paganelli F, Arpin-Bornet M, Auquier P, Sampol J, Dignat-George $F$, et al. Vasodilator-stimulated phosphoprotein phosphorylation analysis prior to percutaneous coronary intervention for exclusion of postprocedural major adverse cardiovascular events. J Thromb Haemost. 2007;5:1630-6.

11. Lamberts M, Gislason GH, Lip GY, Lassen JF, Olesen JB, Mikkelsen AP, et al. Antiplatelet therapy for stable coronary artery disease in atrial fibrillation patients taking an oral anticoagulant: a nationwide cohort study. Circulation. 2014;129:1577-85.

12. Karjalainen PP, Porela P, Ylitalo A, Vikman S, Nyman K, Vaittinen MA, et al. Safety and efficacy of combined antiplatelet-warfarin therapy after coronary stenting. Eur Heart J. 2007;28:726-32.

13. Ruiz-Nodar JM, Marín F, Hurtado JA, Valencia J, Pinar E, Pineda J, et al. Anticoagulant and antiplatelet therapy use in 426 patients with atrial fibrillation undergoing percutaneous coronary intervention and stent implantation implications for bleeding risk and prognosis. J Am Coll Cardiol. 2008;51:818-25.

14. Gilard M, Blanchard D, Helft G, Carrier D, Eltchaninoff H, Belle L, et al. Antiplatelet therapy in patients with anticoagulants undergoing percutaneous coronary stenting (from STENTIng and oral antiCOagulants [STENTICO]). Am J Cardiol. 2009;104:338-42.

15. Mennuni MG, HalperinJL BS, Schoos MM, Theodoropoulos KN, Meelu OA, et al. Balancing the risk of bleeding and stroke in patients with atrial fibrillation after percutaneous coronary intervention (from the AVIATOR registry). Am J Cardiol. 2015;116:37-42.

16. Sambola A, Mutuberría M, García Del Blanco B, Alonso A, Barrabés JA, Alfonso $F$, et al. Effects of triple therapy in patients with non-valvular atrial fibrillation undergoing percutaneous coronary intervention regarding thromboembolic risk stratification. Circ J. 2016;80:354-62.

17. Fiedler KA, Maeng M, Mehilli J, Schulz-Schüpke S, Byrne RA, Sibbing D, et al. Duration of triple therapy in patients requiring oral anticoagulation after drug-eluting stent implantation: the ISAR-TRIPLE trial. J Am Coll Cardiol. 2015;65:1619-29.

18. Koskinas KC, Räber L, Zanchin T, Pilgrim T, Stortecky S, Hunziker L, et al. Duration of triple antithrombotic therapy and outcomes among patients undergoing percutaneous coronary intervention. JACC Cardiovasc Interv. 2016;9:1473-83.

19. Gao F, Zhou YJ, Wang ZJ, Shen H, Liu XL, Nie B, et al. Comparison of different antithrombotic regimens for patients with atrial fibrillation undergoing drug-eluting stent implantation. Circ J. 2010;74:701-8.

20. Suh SY, Kang WC, Oh PC, Choi H, Moon Cl, Lee K, et al. Efficacy and safety of aspirin, clopidogrel, and warfarin after coronary artery stenting in Korean patients with atrial fibrillation. Heart Vessel. 2014;29:578-83.
21. Angiolillo DJ, Fernandez-Ortiz A, Bernardo E, Alfonso F, Macaya C, Bass $T A$, et al. Variability in individual responsiveness to clopidogrel: clinical implications, management, and future perspectives. J Am Coll Cardiol. 2007:49:1505-16

22. Mega JL, Close SL, Wiviott SD, Shen L, Hockett RD, Brandt JT, et al. Cytochrome p-450 polymorphisms and response to clopidogrel. N Engl J Med. 2009;360:354-62.

23. Wang XD, Zhang DF, Liu XB, Lai Y, Qi WG, Luo Y, et al. Modified clopidogrel loading dose according to platelet reactivity monitoring in patients carrying $A B C B 1$ variant alleles in patients with clopidogrel resistance. Eur J Intern Med. 2012;23:48-53.

24. Fontana P, Dupont A, Gandrille S, Bachelot-Loza C, Reny JL, Aiach M, et al. Adenosine diphosphate-induced platelet aggregation is associated with P2Y12 gene sequence variations in healthy subjects. Circulation. 2003;108:989-95.

25. Strisciuglio T, Barbato E, De Biase C, Di Gioia G, Cotugno M, Stanzione R, et al. T2238C atrial natriuretic peptide gene variant and the response to antiplatelet therapy in stable ischemic heart disease patients. J Cardiovasc Transl Res. 2018;11:36-41.

26. Zhang S, Zhu J, Li H, Wang L, Niu J, Zhu B, et al. Study of the association of PEAR1, P2Y12, and UGT2A1 polymorphisms with platelet reactivity in response to dual antiplatelet therapy in Chinese patients. Cardiology. 2018; 140:21-9.

27. Price MJ, Berger PB, Teirstein PS, Tanguay JF, Angiolillo DJ, Spriggs D, GRAVITAS Investigators, et al. Standard- vs high-dose clopidogrel based on platelet function testing after percutaneous coronary intervention: the GRAVITAS randomized trial. JAMA. 2011;305:1097-105.

28. Collet JP, Cuisset T, Rangé G, Cayla G, Elhadad S, Pouillot C, et al. ARCTIC investigators. Bedside monitoring to adjust antiplatelet therapy for coronary stenting. N Engl J Med. 2012;367:2100-9.

29. Trenk D, Stone GW, Gawaz M, Kastrati A, Angiolillo DJ, Müller U, et al. A randomized trial of prasugrel versus clopidogrel in patients with high platelet reactivity on clopidogrel after elective percutaneous coronary intervention with implantation of drug-eluting stents: results of the TRIGGER-PCI (testing platelet reactivity in patients undergoing elective stent placement on Clopidogrel to guide alternative therapy with Prasugrel) study. J Am Coll Cardiol. 2012;59:2159-64.

30. Cayla G, Cuisset T, Silvain J, Leclercq F, Manzo-Silberman S, Saint-Etienne C, et al. ANTARCTIC investigators. Platelet function monitoring to adjust antiplatelet therapy in elderly patients stented for an acute coronary syndrome (ANTARCTIC): an open-label, blinded-endpoint, randomised controlled superiority trial. Lancet. 2016;388:2015-22.

31. Connolly S, Pogue J, Hart R, Pfeffer M, Hohnloser S, Chrolavicius S, et al. Clopidogrel plus aspirin versus oral anticoagulation for atrial fibrillation in the atrial fibrillation Clopidogrel trial with Irbesartan for prevention of vascular events (ACTIVE W): a randomised controlled trial. Lancet. 2006;367:1903-12.

32. Zahger $D$, llia R. Coronary stenting in warfarin treated patients. Euro Intervention. 2009;5:277-81.

33. Holmes DR Jr, Kereiakes DJ, Kleiman NS, Moliterno DJ, Patti G, Grines CL. Combining antiplatelet and anticoagulant therapies. J Am Coll Cardiol. 2009;54:95-109.

34. Lip GY, Huber K, Andreotti F, Arnesen H, Airaksinen KJ, Cuisset T, et al. European Society of Cardiology Working Group on Thrombosis. Management of antithrombotic therapy in atrial fibrillation patients presenting with acute coronary syndrome and/or undergoing percutaneous coronary intervention/ stenting. Thromb Haemost. 2010;103:13-28.

35. Flaker GC, Gruber M, Connolly SJ, Goldman S, Chaparro S, Vahanian A, et al. Risks and benefits of combining aspirin with anticoagulant therapy in patients with atrial fibrillation: an exploratory analysis of stroke prevention using an oral thrombin inhibitor in atrial fibrillation (SPORTIF) trials. Am Heart J. 2006;152:967-73.

36. Dewilde WJ, Oirbans T, Verheugt FW, Kelder JC, De Smet BJ, Herrman JP, et al. Use of clopidogrel with or without aspirin in patients taking oral anticoagulant therapy and undergoing percutaneous coronary intervention: an open-label, randomised, controlled trial. Lancet. 2013;381:1107-15.

37. Sibbing D, von Beckerath N, Morath T, Stegherr J, Mehilli J, Sarafoff N, et al. Oral anticoagulation with coumarin derivatives and antiplatelet effects of clopidogrel. Eur Heart J. 2010;31:1205-11.

38. Sarafoff N, Martischnig A, Wealer J, Mayer K, Mehilli J, Sibbing D, et al. Triple therapy with aspirin, prasugrel, and vitamin $\mathrm{K}$ antagonists in patients with drug-eluting stent implantation and an indication for oral anticoagulation. J Am Coll Cardiol. 2013;61:2060-6. 
39. Jackson LR 2nd, Ju C, Zettler M, Messenger JC, Cohen DJ, Stone GW, et al. Outcomes of patients with acute myocardial infarction undergoing percutaneous coronary intervention receiving an oral anticoagulant and dual antiplatelet therapy: a comparison of clopidogrel versus prasugrel from the TRANSLATE-ACS study. JACC Cardiovasc Interv. 2015;8:1880-9.

40. Cannon CP, Bhatt DL, Oldgren J, GYH L, Ellis SG, Kimura T, et al. RE-DUAL PC Steering Committee and Investigators. Dual antithrombotic therapy with dabigatran after PCl in atrial fibrillation. N Engl J Med. 2017;377:1513-24.

41. Gibson CM, Mehran R, Bode C, Halperin J, Verheugt FW, Wildgoose P, et al. Prevention of bleeding in patients with atrial fibrillation undergoing PCI. N Engl J Med. 2016;375:2423-34.

- fast, convenient online submission

- thorough peer review by experienced researchers in your field

- rapid publication on acceptance

- support for research data, including large and complex data types

- gold Open Access which fosters wider collaboration and increased citations

- maximum visibility for your research: over $100 \mathrm{M}$ website views per year 